\title{
Ideas and Suggestions on Sustainable Development of Undergraduates' Human Capital from the Perspective of Supply-side Structural Reform
}

\author{
Jiandong Zhang \\ Dalian Polytechnic University \\ Dalian, China \\ Xiaolin Liu \\ Dalian Polytechnic University \\ Dalian, China
}

\author{
Yue Qi* \\ Dalian Polytechnic University \\ Dalian, China \\ *Corresponding Author \\ Yangyang Si \\ Dalian Polytechnic University \\ Dalian, China
}

\begin{abstract}
Human capital plays an important role in the development of social industry. High-quality skilled personnel are the basis for innovation in industry. At present, it is difficult to balance the supply and demand for human capital in the industrial application. The main reason is just difficult for the human capital cultivated by the education system to correspond with the demand of enterprises in a short time, and there are problems in the sustainable development of human capital of college students in our country. Therefore, a joint training mechanism should be established to promote the sustainable development of human capital.
\end{abstract}

Keywords-supply side; reform, human capital; sustainable improvement; high-tech application talents; school -enterprise cooperation

\section{INTRODUCTION}

At present, the world economic situation has undergone drastic changes and reorganizations. China faces a new normal economic situation and proposes a corresponding plan: Shift slowdown and optimization of structure; foster new growth points and form new momentum. Power conversion is at the heart of structural adjustment. The 19th National Congress of the Communist Party of China pointed out: Building a strong nation for education is a basic project for the great rejuvenation of the Chinese nation. Education must be given priority in order to speed up the modernization of education and ensure people's satisfaction with schooling. We should perfect the vocational education and training system, deepen the integration of production and teaching, and the cooperation between schools and enterprises. Under the guidance of the goal of becoming a powerful country, in the past higher education system, we experienced enlarging the enrollment scale and vigorously developing the scale of higher education so that in 2009, the gross enrollment rate of higher education in our country will reach $24.2 \%$ and the number of graduates will stay at a high level no less, becoming the largest country in higher education. Although enlarging the enrollment scale makes more people have the opportunity to receive higher education and greatly optimize their social status through higher education, there is a structural problem of personnel training: the imbalance between supply and demand for human capital. Therefore, based on the gradual improvement and cultivation of human resources for undergraduates, it is helpful to solve the problem of kinetic energy under the new habitual economy.

\section{INNOVATIVE IDEAS FOR SUSTAINABLE DEVELOPMENT OF HUMAN CAPITAL}

The sustainable growth of college students' human capital means that under the guidance of cultivating talents who respond to the needs of the market, the ability of college students should be further improved to become high-tech application talent. To this end, the following opinions:

There is marked school-enterprise cooperation Cooperation between schools and enterprises to achieve the "joint training" system can be reflected in the qualification certificates so that graduates have "evidence" and "imprints" in their hands when they are employed. Avoid the "certificate" guidance, the implementation of multiple assessment system, the skills refinement; refer to "job analysis" to weigh the various competency indicators and to be assessed, evaluation methods used to choose a structured assessment to eliminate personal bias and training. Cumulative number of skills before passing the certificate could enhance the gold content of the certificate and market reputation.

School-enterprise two-way production and teaching from the perspective of integration. Theoretical knowledge and job requirements are never mutually exclusive extremes. In the process of theoretical training, students should be encouraged to have an in-depth understanding of the major and look at the meeting point between the target and the career development. Big and empty, high and not low is on 
the situation. In the job internship should find the blind spot in the field of expertise to achieve the lack of inspection, to ensure that undergraduate education of human capital to achieve job-building skills upgrading, professional threedimensional, application, that is, to enhance the sustainable development of human capital and develop high-tech applications Talent.

Innovative education-led human capital development is shown. To achieve innovative education there are two principal points: First, the practicality of academic education, and second, to deal with the timeliness of industrial demand. The former focuses on the removal of barriers between disciplines, education should ensure structural optimization, core curriculum to maintain the characteristics of ordinary course to penetrate and broaden, to achieve a multi-skill. Avoid postgraduates are still undergraduate education knowledge, to extend the years cannot get the corresponding level of education lag, we should realize the sustainable development of human capital, training of high-tech application personnel. The latter stresses timeliness: a lot of things are rapidly changing in the Internet era, the school's education should closely follow the social and economic development, but also pay attention to advancing with the times, for lecturers also have regular training and inspection, otherwise there will be "Failure "risk.

\section{ANALYSIS ON THE WAY OF HUMAN CAPITAL SUSTAINABLE DEVELOPMENT}

It should use SPSS to complete the analysis of variance of the sustainable increase of human capital through schoolenterprise cooperation. 1 = central enterprises, state-owned enterprises, institutions, 2 = large privately-owned wellknown companies, $3=$ small and medium-sized private companies, 4 = Hong Kong, Macao and Taiwan funded, 5 = Foreign Investment, $6=$ others.
TABLE I. QUANTITATIVE ANALYSIS OF THE WAYS IN WHICH BUSINESS EXPECTATIONS AND UNIVERSITY COOPERATION ARE ANALYZED

\begin{tabular}{|l|l|l|l|l|l|}
\hline \multicolumn{7}{|c|}{ ANOVA } \\
\hline & Sum of Squares & df & Mean Square & F & Significance \\
\hline Between Groups & 86.478 & 5 & 17.296 & 14.962 & 0.000 \\
\hline Within Groups & 376.878 & 326 & 1.156 & & \\
\hline Total & 463.356 & 329 & & & \\
\hline
\end{tabular}

In "Table I", there is one row between groups, the sum of squares $\mathrm{SSA}=86.478$, degree of freedom $\mathrm{df}=\mathrm{k}-1=6-1=5$, $\mathrm{k}$ is the number of factors, that is, Mean Square MSA = 17.296.

Within Groups, Sum of Squares SSE $=376.878$, degrees of freedom $\mathrm{df}=\mathrm{nk}=330-4=326$, where $\mathrm{n}$ is the number of all samples, Mean Square MSE $=1.156$

Total one line, Sum of Squares $=\mathrm{SSA}+\mathrm{SSE}=86.478+$ $376.878=463.356$, degrees of freedom $\mathrm{df}=\mathrm{n}-1=330-1=$ 329.

$\mathrm{F}$ statistic $=$ MSA $/ \mathrm{MSE}=14.962, \mathrm{~F}$ statistic is greater than the critical value F0.05 $(5,326)$, indicating that it falls into the rejection domain. Sig value $=0.000<0.05$, rejected the null hypothesis, and considered that there are significant differences between the six types of enterprises in the form of ownership and the number of ways in which they expect to cooperate with colleges and universities.

The above results show that colleges and universities should pay more attention to finding a school-enterprise cooperation enterprise. The statistical results show that the "central SOEs, state-owned enterprises and institutions", "large privately-owned well-known companies" and "small and medium private-owned companies" Intentions are strong, while "Hong Kong, Macao and Taiwan funded enterprises" "foreign-funded enterprises" to accept the cooperation of the less. When seeking cooperation with enterprises, colleges and universities need to take into account their own professional types as well as the wishes of different types of enterprises. Thus, the success rate of focusing on "casting nets" will be even higher.

TABLE II. CROSS-TABULATION OF ACADEMIC QUALIFICATIONS AND POSITIONS

\begin{tabular}{|c|c|c|c|c|c|c|}
\hline \multicolumn{7}{|c|}{ Cross tabulation } \\
\hline \multicolumn{7}{|l|}{ count } \\
\hline & & \multicolumn{4}{|c|}{ Your position is: } & \multirow[t]{2}{*}{ Total } \\
\hline & & General staff & Grassroots managers & Middle and senior management & Others & \\
\hline \multirow{3}{*}{$\begin{array}{l}\text { Your highest } \\
\text { education: }\end{array}$} & Undergraduate and below & 37 & 75 & 31 & 4 & 147 \\
\hline & Master graduate student & 39 & 72 & 45 & 5 & 161 \\
\hline & PhD and above & 10 & 13 & 55 & 2 & 88 \\
\hline \multicolumn{2}{|l|}{ Total } & 89 & 178 & 110 & 11 & 388 \\
\hline
\end{tabular}

In the question "Your highest education level" and "Your job is", according to the data, it is clear from the data that 55 people, accounting for $62.5 \%$ of the middle and top management, Among the postgraduates, there are 72 people at the grassroots level, accounting for $44.7 \%$, followed by 45 at the middle and top level, accounting for $28 \%$ of the total, while those with undergraduate education and below have a clear lag in the proportion of managers the other two as in
"Table II". It can be drawn, the higher the qualifications, the more prospective career prospects, the higher the space for job postings. In other words, the sustainable growth of the human capital of college students is to make them move towards the direction of high-tech application talents. 
IV. THE STRUCTURAL REFORM OF SUPPLY-SIDE PERSPECTIVE ON THE Sustainable DEVELOPMENT OF College Students' Human Capital Proposals

In the face of the economic turmoil under the new normal economic conditions, the education system of fluctuating industries should not be confused, the laws of the market should be grasped, the new situation should be stabilized, and measures should be taken in response to national conditions and structural problems. Industry and education, schools and enterprises are ultimately nothing more than the game between the suppliers of market labor and the consumers of labor, and the integration of knowledge and practice. Both top-down management and bottom-up feedback is a complicated process. Although the strategic partnership's cooperation and business accomplishments are important, the impetus for future growth and competitive advantage are even more important. It precisely comes from the interaction with young people and the training consultation. The research conclusion has many meanings and has the following suggestions:

\section{A. The Government Strongly Supports}

From an economic development point of view, the government has always been a third-party group that guides workers and workers. Long-term, stable development of school-enterprise cooperation is inseparable from government policies. The government grants tax-exempt businesses, Subsidies can play a more positive role in guiding, while increasing the willingness of enterprises to cooperate. Furthermore, the government should vigorously support the "Internet +" new training model, bringing a large amount of high-tech human capital to the market in response to the sharing of economic, platform-based economy and digital economy models and expanding the coverage of free education or low-cost education in response to the scarcity of resources.

\section{B. Fixed-point Investment Business, Professional Link to form the Employer Brand}

The optimization effect of human capital sustainable development is not one-way. The improvement of educational skills has made a significant contribution to the upgrading of innovation and industrial optimization. Dominant effect, it can help enterprises link high-quality human capital, that is, high-tech application personnel; but also stimulate a wide range of human capital mapping contribution to promote economic development; recessive effect, human capital often contains the enterprise can the ability to innovate that is sustainably managed and its core competitiveness continues to evolve will not only meet the needs of the industry but also promote economic development. However, the integration of labor and education is not a "wide-spread network." It is necessary to take a professional-oriented and targeted training and make key investments in the superior disciplines of colleges and universities. Focusing on those with outstanding performance, high-quality personnel are transformed from employment-oriented technical talents Lead to the core business-oriented talent, work together to bring about employment.

Employment is a double-selection process. While human capital is continuously improving, enterprises that conduct school-enterprise cooperation form employers' brands through word-of-mouth, innovative ability improvement and education investment in higher education. An employer's brand as an intangible asset in the labor market undoubtedly raises the level of recognition in the labor market. Enhance the image of the reputation and reputation of the brand in the talent market based on the employer as the main body, highquality human resources as the carrier, staff services based on staff.

\section{School Promotion, Forming a Virtuous Circle}

A good employer image can bring a premium for the enterprise in the market, create service brand advantage for the outside and attract talents in the labor market internally. Cultivation of high-quality human capital can optimize and integrate the education system and raise the popularity of educating higher education institutions, to enhance educational information internally, and more importantly, a more integrated three-pronged education and teaching system can cultivate experienced college students in advance, adapt to industrial knowledge-oriented management practices in advance and improve the level of emotional management; at the same time, tap social roles, internal drive and attitude such as the ability to differentiate to promote and become a positive recipient of education and training, professional cognitive and career planning in advance. The integration of the two individuals can create environment and new thinking, supply China with the necessary internal innovations and win the attention of the public sector and social capital, so as to promote the sustainable increase of human capital and create a virtuous circle.

\section{CONCLUSION}

Supply-side reform should be guided by the market, meet the needs of industrial development, integrate production and teaching, and collaborate with schools and enterprises in training high-tech applied talents so as to enhance the sustainable development of human capital.

\section{REFERENCES}

[1] Xi Jinping Decides to Build a Well-off Society in an All-round Way to Win the Great Victory of Socialism with Chinese Characteristics in a New Era - Report on the 19th National Congress of the Communist Party of China [J]. China Economic Weekly, 2017, (42): 68- 96.

[2] 2016 study report: one out of every four students from China [J] Yunnan Education (Vision Integration), 2017, (01): 5.

[3] Wang Zhichen. Study on the Improvement of Undergraduates' Employment and Entrepreneurial Capability under Supply-side Reform [J]. Journal of Shijiazhuang Railway Institute (Social Sciences Edition), 2017,11 (02): 102-105.

[4] Chen Zuji. Media professionals how to adapt to "financial media" era [N]. China Education Daily, 2010-12 (005).

[5] CHEN Zu-ji. College media major should be guided by the marke dynamics - A case study of Radio and Television School of Chengdu 
University of Technology [J]. Education and Research Research, 2010,24 (07): 70-73.

[6] Peng Jian-feng. New thinking of human resource management in Internet age [J]. China Human Resource Development, 2014, (16): 69.

[7] Zhang Fenglin. Human capital theory and its application [M], Commercial Press, April 2006, P61. [8] David P. Repak, Scott A.Snell. Virtual HR: Strategic Human Resource Management in the 21st Centruy [J]. Human Resource Management Review, 1998, 8 (3): 215-236. 